\title{
XLI. Wave propagation of magnetism
}

\section{John Trowbridge}

To cite this article: John Trowbridge (1892) XLI. Wave propagation of magnetism, Philosophical Magazine Series 5, 33:203, 374-378, DOI: 10.1080/14786449208620005

To link to this article: http://dx.doi.org/10.1080/14786449208620005

$$
\text { 曲 Published online: } 08 \text { May } 2009 .
$$

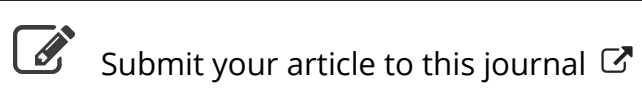

\footnotetext{
山 Article views: 2
}

Q View related articles $\sqsubset$ 


\section{$\left[\begin{array}{ll}374 & ]\end{array}\right.$}

\section{Wave Propagation of Magnetism. $B y$ JoHN Trowbridge *.}

$V^{\top}$ RIOUS attempts have been made to discover a wavepropagation of magnetism along bars of iron or around rings of this metalt. The ordinary method of investigation has been to subject the iron to alternating currents of a certain frequency, and to search for nodes along the extent of the bar or ring. The search has been conducted by employing small secondary coils of wire connected with a ballistic galvanometer or with telephones.

I have lately examined this question with a new instrument which I have termed a phasemeter, and which seems to me to be of great use in the subject of alternating currents. It consists of an application of Lissajous's method of studying the vibration of tuning-forks to two telephones which take the place of the tuning-forks. On the diaphragm of each telephone is affixed a mirror; and the axes of the telephones are so turned that the excursions of a spot of light, reflected from both the mirrors of the telephones, represent the figure produced by a combination of two motions at right angles to each otber. In the telephone which I have employed, the diaphragms are about three inches in diameter, and are clamped delicately around the edges upon their support by little screw-clamps, which can be moved about until the diaphragm vibrates in unison with the alternating currents which are employed. Professor Eli W. Blake $\ddagger$ has described a method of making the vibrations of a telephone-diaphragm visible. And since I began to work upon this subject M. Wien $\S$ has described an instrument which he terms an optical telephone, which he employs for the measurement of alternating currents. In his method a stylus connected with the centre of the diaphragm tonches a light mirror which is placed upon a flexible support, and thus the motions of the diaphragm are amplified. Great care must evidently be taken that the support of the mirror should move in unison with the stylus connected with the diaphragm. Professor Blake's method is an extremely sensitive one : for my purposes, however, I have found the method of clamping the diaphragm around its edges at suitable points sufficiently sensitive, and I

* Communicated by the Author.

$\dagger$ Dr. Harold Whiting, Proc. American Academy of Arts and Sciences, p. 14 (1881); F. T. Trouton, ' Nature,' November 1891.

$\ddagger$ American Journal of Science, vol. xvi. (1878).

\$ Ann. der Physik und Chemie, No, 12 (1891). 
have not been troubled by the vibration of supports or disturbances in the room where the instrument was set up. The two telephones can be mounted upon the same support, and the entire instrument can be comprised in a box a foot square. I have used as a source of light a Welsbach burner, which consists of a fine gauze of zirconium placed in the flame of a Bunsen burner. A tin chimney provided with a circular opening of about $\frac{1}{2}$ inch in diameter is placed over a glass chimney and a cylinder of writing-paper over the tin cylinder; a pinhole in the paper at the centre of the orifice in the tin chimney enables one to obtain a point of light on a light ground. This light ground diminishes diffraction-effects and enables one to see the cross wires of an observing-telescope or microscope. With a lime-light or electric light the difference of phase between branch circuits and main circuits through which alternating currents are pulsating can be shown to a large audience. On account of its application to the study of difference of phase in magnetic researches, I have termed the instrument a phasemeter. It is evident that it can be used to study the nodal lines of membranes and plates : for this purpose a plate or membrane provided with a mirror might be placed in front of a movable magnet containing at its end a coil of wire, and the vibrations of any membrane or thin plate could be compared with those of the diaphragm of a fixed and standard telephone.

I have also employed the instrument for studying differences in phase between branch circuits. That there are such differences of phase has been shown by Lord Rayleigh and others. This portion of my investigation I reserve for a subsequent paper.

The phasemeter permits of the study of the effect of different qualities of iron and steel in increasing the self-induction of, and therefore the impedance of, branch circuits; and it seems to me can be made of great use in the study of alternating-current motors. It is well known that two or three electrodynamometers must be employed in the ordinary methods of determining change of phase. The phasemeter can be quickly employed and its adjustments are extremely simple. The application of this instrument to the question of magnetic waves is the subject of this paper. I have employed it both on rings and straight bars, laminated and solid. The ring I employed was 3 feet in diameter, and the diameter of its cross section was $\frac{1}{2}$ inch. Two large coils of coarse wire were slipped upon the ring, through which an alternating current could be passed. These coils could be separated or joined together, and by a commutator opposite 
poles or poles of the same name could be opposed. Two small coils of fine wire were also slipped upon the ring; each of these small coils was connected with a telephone. The diaphragm of one telephone gave a horizontal line of light, and the diaphragm of the other a vertical line, the combination of the two amplitudes giving a straight line, an ellipse, or a circle.

On placing one of the small coils at a fixed point on the ring on one side of one of the large coils and the other small coil between the two large coils, I examined the distribution of magnetism between the coils when the same poles or opposite poles were opposed to each other. A preliminary experiment in which the two small fine coils were on the same side of one of the large coils gave me no indication of nodes, or change of phase.

When, however, one coil was placed in the manner I have described between the two coils, and one on the opposite side of either of the coils, the following phenomena, which are sufficiently obvious, were observed. With a current of 2500 alternations per minute, an ellipse was seen in the phasemeter when the coils were at an equal distance from the ends of either of the large coils. When poles of the same name were opposed to each other, this ellipse changed from an ellipse with its major axis inclined to the right to an ellipse with this axis inclined to the left or the reverse, thus indicating a difference of phase of $180^{\circ}$.

At the central point on the iron between the two poles of the same name, the small coil placed there indicated no lines of force threaded through it, and consequently the telephone connected with this coil gave no amplitude, and a line of light either horizontal or vertical was given by the other telephone. When poles produced by the current in the large coils were of opposite sign, there was no appreciable change of phase produced by moving one of the small coils on the iron between these poles; only the amplitude of the diaphragm of the telephone connected with it changed.

The reason of the change of phase in the first case is obvious. In the case of two poles of the same sign which are opposed, the lines of force are threaded through the coil in one direction on one side of the middle point of the iron between the coils, and in the opposite direction on the other side of this middle point. With poles of opposite sign opposed, the lines of force are threaded in the same direction in whichever way the small coil is moved between these poles. The same phenomena can be observed on straight bars. An interesting manner of showing the change of phase produced 
by the opposition of poles of the same or contrary sign, is to place one of the small coils on the core of a large coil, at one end of this latter coil, and to place the other small coil on a small rod of iron or steel, and to bring this rod with its coil near one end of the core of the large coil and afterwards to the other end. The change of phase of the ellipses is readily shown, and is evidently due to the threading of the lines of force by induction through the small coils in the same or in opposite directions.

If an incandescent lamp of about one-candle power is connected with one of the small coils, and the coil is placed on the iron ring between poles of the same name, the lamp will not glow ; but on changing the poles so that two of opposite sign shall be opposed, the lamp immediately glows. This point, however, cannot be called a true nodal point, and I failed to find any other. Although it is probably true that the most distant molecule of the iron quivered under the periodic alternations of magnetism to which it was subjected, yet there was no wave-motion along the iron ring. Just as a distant molecule might have responded quickly to the first application of heat to the ring, there is no true wave-motion in the propagation of the heat. It seems to me that the propagation of magnetic disturbances produced by forced oscillations on iron bars is closely analogous to the propagation of heat over these bars, and that each molecule of the iron swings under the directive moment of the magnetic field somewhat like a pendulum in molasses.

Instead of the formula

$$
\frac{d^{2} u}{d t^{2}}+k \frac{d u}{d t}+n^{2} u=\mathrm{E} \cos p t
$$

we have

$$
\frac{d^{2} u}{d t^{2}}+k \frac{d u}{d t}+n^{2} u=0
$$

The curve of distribution of magnetism on the ring can be made to agree closely with an exponential form, which is evidently the solution of the second of the above equations.

The projection of the ellipses on a screen makes a very interesting lecture-experiment.

To ascertain whether changes of phase could be detected between the inner portions of a thick iron core subjected to alternating magnetic impulses and the outside of this core, I placed one of the coils of the phasemeter in a channel which was turned about the centre of a core of iron, the diameter of the curve being $2 \frac{1}{2}$ inches. Another coil with its centre 
coinciding with the centre of the imbedded coil was slipped on the outside of the core: no changes of phase could be observed between the inner portions of the iron core and the outside portions. When an armature was placed over the imbedded coil, thus completely closing it in iron, hardly any lines of force were threaded through it. They were diverted to the surface of the iron core. Here we had the case of Thomson's marine galvanometer, and the amplitude shown by the telephone-diaphragm connected with the imbedded coil was reduced to almost nothing. When, however, the armature which extended over the entire cross section of the core was removed and an armature was employed which extended the iron which passed through the centre of the imbedded coil beyond the limits of the ends of the thick core, the lines of magnetic force were brought down from the surface of the iron and made to thread themselves through the imbedded coil. Properly chosen armatures can be made to closely resemble arrangements of lenses, bringing magnetic lines into bundles or spreading them. An incandescent lamp can thus be made to glow when it is connected with a coil imbedded in iron, by diverting the lines of magnetic induction through it with suitable armatures. To illustrate the distribution of the lines of force about an electromagnet, one can employ the phasemeter to advantage. By reducing the diameter of the iron ring on which the coils II bave described are slipped, so that a sufficient number of lines of force are threaded from the north pole to the south pole of one of the large coils, one can show that an incandescent lamp can be lighted even when it is outside the coil in a plane perpendicular to the axis of one of the large coils and passing through its centre. It is evident that there would be no induction through the coil if the iron did not make a magnetic circuit.

The experiments I have described were conducted with an alternating machine giving currents of the period of 2500 to 5000 a minute. Doubling the rate of alternation only produced changes in amplitude.

Dr. Harold Whiting, in the paper I have cited, could find no true nodes in the propagation of magnetism along bars, and my instrument also shows none; and my conclusion is that which I have already given, namely that the propagation of magnetic induction in iron and steel is expressed by the equation of motion of molecular magnets in a resisting medium rather than by the equation of a wave-motion.

Jefferson Physical Laboratory, Cambridge, Mass., U.S. 